\title{
Performance Evaluation and Optimization of Wind-Solar PV Hybrid Electricity Generation and Application to Electric Vehicle
}

\author{
Gado Abubakar, ${ }^{1,2}$ Anbazhagi Muthukumar ${ }^{1} \mid$ Abdullahi B. $U^{2,3} \mid$ Muthukumar Muthuchamy ${ }^{2}$ \\ ${ }^{1}$ Department of Environmental Science, School of Earth Science Systems, Central University of Kerala, Kasaragod, Kerala, \\ India \\ ${ }^{2}$ Department of Physics, Kebbi State University of Science and Technology, Aliero, Kebbi State, Nigeria \\ ${ }^{3} \mathrm{CoE}-$ Renewable and Sustainable Energy Studies, Suresh Gyan Vihar University, Jagatpura, Jaipur, Rajasthan, India.
}

To Cite this Article

Gado Abubakar, Anbazhagi Muthukumar, Abdullahi B.U and Muthukumar Muthuchamy, "Performance Evaluation and Optimization of Wind-Solar PV Hybrid Electricity Generation and Application to Electric Vehicle", International Journal for Modern Trends in Science and Technology, Vol. 06, Issue 06, June 2020, pp.:161-177; https://doi.org/10.46501/IJMTST060631

Article Info

Received on 20-May-2020, Revised on 02-June-2020, Accepted on 14-June-2020, Published on 24-June-2020.

\section{ABSTRACT}

Electricity and transportation sectors are responsible for a significant percentage of the global energy-related greenhouse gases emission, and their emissions are increasing at a faster rate in comparison to other sources. Among all the sustainable solutions to energy-related emissions, Hybrid Renewable Energy Systems (HRES) are becoming a more effective option for rural electrification and other energy-related applications. This paper presents a novel approach for the performance analysis of HRES for electricity generation for typical household electricity generation and application to mini electric campus shuttle. Different benchmark models are employed in the modelling, simulation and validation of the designed HRES. The simulation results obtained on the designed HRES demonstrated the effectiveness of all the adopted methods in enhancing the modelling accuracy of renewable electricity systems in electricity generation. The technical analysis of the system based on the simulation and the validation results demonstrated that the system could deliver the full electricity demand of typical household as well as, the total electricity demand of BSC-P1 electric campus shuttle. Additionally, 100\% Battery Energy Storage System (BESS) charging was achieved and the battery capacity was never reached at all-time indicating the viability of the system in supplying uninterrupted power to the electricity demand.

KEYWORDS: Renewable energy; Electric vehicles; Wind-solar PV hybrid; Cubic spline interpolation; Microgeneration

Copyright (C) 2014-2020 International Journal for Modern Trends in Science and Technology

DOI: https://doi.org/10.46501/IJMTST060631

\section{INTRODUCTION}

Sustainable electricity and transportation have become the grand challenges of the twenty-first century from the political, economic and societal point of view [1]. Utilization of fossil fuels for transportation and energy-related issues is among the biggest culprit of anthropogenic carbon emission, accounting for about $60 \%$ of the global 
$\mathrm{CO}_{2}$ emission. Electricity as the backbone of development of any society has already contributed $37.5 \%$ of the total global $\mathrm{CO}_{2}$ emission releasing about 7700 million tons of $\mathrm{CO}_{2}$ annually [2, 3, 4, 5]. To address this challenging issue, renewable energy technologies are highlighted as the potential solutions to sustainable electricity generation for large, medium and small-scale electricity generation $[6,7,8,9]$. Renewable energy sources such as wind energy, solar energy, small hydro, geothermal energy, etc. are clean energy sources that offer the promise of meeting energy demand for both on-grid and off-grid applications as well as, application to EVs (Electric Vehicles) [10]. Although renewable energy sources are intermittent in nature, looking at renewable energy sources potential at diurnal level (i.e. the hourly level of generation) and complimenting different renewable energy technologies in the form of hybrid, solve the effect of intermittency of renewable energy sources in electricity generation [11].

Hybrid Renewable Energy Systems (HRES) such as wind-solar hybrid are among the most promising renewable electricity generation sources in the context of sustainability to the environment. This is because, in most of the hybrid case studies, nearly all the traditional intermittency effect of the traditional standalone renewable electricity generation systems are solved [12]. HRES have been developed and practically confirmed to generate autonomous, stable and sustainable power for both on-grid and off-grid applications $[13,14,15]$. The benefit of HRES especially in the rural electrification where the majority of the populations living off-grid are low-income houses in the villages where most of the renewable energy resources are readily available, and cheaper to explore in comparison to grid expansion $[13,14$, $15,16]$.

To improve the accuracy of renewable hybrid technologies, enormous research studies are available in the area of HRESs on stabilizing hybrid power output and improving the overall performance of the system. Ding et al. [17] conducted a study on the economic and system performance of the wind-solar thermal hybrid system in Zhangbei China. The study revealed that the hybrid system has the highest net present value compared to the conventional coal-fired power plant, in addition to the huge carbon emission reduction. Stroe et al. [18] analysed the operational reliability of the wind-solar PV hybrid system integrated with the Li-ion battery storage system for mitigating power output variability and ensuring stable and reliable operation of the system studied. The output of the study revealed that the battery capacity was at no time reached, which is indicating the viability of the system in supplying uninterrupted power. Bhattacharjee and Acharya [19] perform a techno-economic analysis of $\mathrm{PV} /$ wind in India using the HOMER simulation environment. The simulation results of the proposed hybrid system show a satisfactory result that can maintain the energy flow to the load at all times. Fathabadi [20] proposed a novel battery/PV/wind hybrid power source equipped with V2G technology to replace the internal combustion engine in a PHEV. The findings of the study revealed that the system could provide high power efficiency in comparison to the conventional combustion engine, in addition to increased cruising range for the PHEV. Baneshi and Hadianfard [21] analyzed HRES comprising $\mathrm{PV} /$ wind/batteries is using HOMER modelling for a non-residential area in southern Iran using demand and peak demand of $9911 \mathrm{kWh}$ and 725 $\mathrm{kW}$ respectively. The study revealed that, with the addition of batteries to the off-grid HRES, the COE decreases with increases in the system reliability. Amutha and Rajini [22] studied the feasibility of solar/wind/hydro based HRES, with a battery as a storage device, for electrification of Kadayam a rural village in Tamil Nadu, India. The study compared the hybrid system with the grid extension using HOMER software. The results of the study revealed that a grid extension is never a suitable option for the selected location with respect to cost effectiveness and environmental protection. The study clearly showed that the hybrid system provides complimentary effect throughout the year by meeting the power demand without any adverse effect on the environment. Carvalho et al. [23] perform a study to evaluate the technical and economic feasibility of wind-PV hybrid systems using a simulation method. The study compared the economic viability of PV power into wind systems under different rated power. The findings of the study revealed that wind energy system is economically ideal and the continuous insertion of PV power into the wind system decreases the chances of profitability although, at some amount of $\mathrm{PV}$ rated power the project maintains a high probability of being successful. Charrouf et al. [24] have performed a study using Artificial Neural Network (ANN) algorithm for the power management of a small-scale Reverse Osmosis (RO) desalination system driven by hybrid wind-solar conversion system with battery bank as 
a storage element. The main objective of the study is to ensure the smooth transfer of the generated power by the hybrid system under the variability and intermittency of the wind speed and the irradiation. The results of the study reveal that energy management by the neural network algorithm allowed the system manage the energy-output-demand balance of the variable exogenous inputs as well as the variable load profiles intelligently while exploiting the information obtained from different inputs. Thierry Odou et al. [25] performs a study to analyse the techno-economic feasibility of hybrid renewable energy system (HRES) for sustainable rural electrification in Fouay village, Benin Republic, Africa. The study utilized HOMER software for optimization, simulation and sensitivity analysis of the system. The findings of the study shows that hybrid solar photovoltaics (PV)/diesel generator (DG) / battery (of $150 \mathrm{~kW} / 62.5 \mathrm{kVA} / 637 \mathrm{kWh}$ ) is the least cost-optimal system and the can ensure a reliable power supply, reduces battery requirements by $70 \%$ compared to $\mathrm{PV} /$ battery system and achieves $97 \% \mathrm{CO}_{2}$ emissions reduction compared to a conventional DG. In the study conducted by Dhunnya et al. [26], an analytical framework is developed using fuzzy logic to evaluate optimal sites for wind, solar and hybrid wind-solar farms; using criteria components for energy optimization through climatological, topographic and human factors. The model is applied through a case study to the Island of Mauritius, which bears a highly complex topography. The output of the study revealed the viability of the methods adopted in identifying the potential sites for hybrid electricity generation. Krishan and Suhag [11], perform a techno-economic analysis of grid-independent hybrid wind-solar PV/ battery system for a very energy-poor community in India, using MATLAB and HOMER simulation software. The findings of the study revealed that the hybrid system was able to maintain the voltage output for the load irrespective of the resources variation. In Tiwary et al. [27], the feasibility of a community-scale hybrid renewable energy system comprising wind-solar PV- biogas generator-battery system was investigated in two European cities Gateshead (UK) and Sofia (Bulgaria) using HOMER simulation method. The outcome of the study revealed that the proposed system could supply the total energy demand of the two cities alongside the huge reduction in biodegradables waste disposal. In the study conducted by Jameel et al. [28], presented a comprehensive

resource

assessment

of

wind-biomass-PV system electricity generation for the local inhabitants of Kallar Kahar village in Punjab Province of Pakistan. The study adopted HOMER Pro software to evaluate the techno-economic feasibility and viability of the system for village electricity application. The result of the study shows that the system can supply the total electricity demand of the village with excess power to the grid. Additionally, Golbarg and Mutasim [29] designed and modelled HRES for the remote area of Ras Musherib a location in the western region of Abu Dhabi, United Arab Emirates using HOMER simulation. The HRES consists of solar PV-wind system-BESS-diesel generators. The findings of the study revealed that the HRES was able to supply the full electricity demand for the designed application with a significant $\mathrm{CO}_{2}$ emission reduction in comparison to using only diesel generators.

It is clear from the literature analysis that huge improvement has been witnessed on the performance of hybrid wind-solar PV in different energy applications. However, the major drawbacks observed in the previous research studies conducted on the feasibility, viability and performance of HRES systems in electricity generation is the absence of in-depth diurnal resource analysis and adequate demand dynamics. Additionally, in the case of HRES application to electric vehicles, Wang et al, [30] performs simulation studies on the potential and performance analysis of WECs in PHEV charging using satellite data obtained from National Renewable Energy Laboratory (NREL). The simulation results show that optimally dispatching the PHEV charging load can significantly reduce the total operating cost of the system. In the study conducted by Denholm et al., [31] on the integration of solar PV system in PHEV charging, the findings of the study revealed that depending on the penetration of each technology, PV could meet all of the increased capacity requirements associated with PHEV deployment, while PHEVs could absorb much, but not all of the potentially curtailed PV generation. Pedro et al., [32] performs modelling and simulation on the potential of the solar PV system in EVs charging in Lisbon, Portugal using satellite data. The findings of the research revealed that using electric vehicles smart charging approach, a $100 \%$ renewable energy-based electricity supply is possible with certain photovoltaics and electric vehicles combinations and that the environmental targets 
to reduce carbon dioxide emissions is possible with significant electric vehicles market share. In the study performed by Nathaniel and Lukas [33], three charging strategies are evaluated for their effect on the interaction between renewable electricity generation and export transmission constraints using the simulation method. The results revealed that these strategies were shown to be effective at addressing grid considerations because using a $10 \% \mathrm{EV}$ adoption rate such charging algorithms could provide 0.6-3MW of additional transmission capacity. In the study conducted by Taibi et al., [34], the potential of introducing EVs into grid sized Hybrid Solar PV-WECs based electricity network is studied using local data in Barbados an island country in the Caribbean region of North America. The study identified that introducing EVs into the grid can provide several benefits without considering the V2G technology. It is shown that EVs can reduce VRE curtailment, increase the average yearly marginal cost of electricity production and finally decrease the needs of grid-connected storage up to a $13 \%$ if EVs are charging during the day. In Domenico [35] dynamic simulation, using TRNSYS environment is employed to investigate the reliability of Solar PV-WECs-BESS-Heat pump hybrid system on EVs charging using Satellite data from meteonorm software. Based on the different employed indicators, the findings of the study revealed that the presence of BESS increases the weekly average reliability of the system for the designed application. Hasan and Hemmati [36] performed a modelling using Mathematical modelling using

Multi-Objective-Techno-Economic-Environmental Optimisation (MOTEEO) on the application of Solar $\mathrm{PV}$ on EVs charging applications in Newcastle, United Kingdom. In this study, a multi-objective-techno-economic-environmental optimisation model is proposed. The results show that the proposed method reduces the energy cost, battery degradation, $\mathrm{CO}_{2}$ emissions and grid utilisation by $88.2 \%, 67 \%, \quad 34 \%$ and $90 \%$ respectively when compared to uncontrolled electric vehicle charging. Based on the reviewed literature on the HRES application to EVs, it is clear that most of the studies are based on simulation of RESs EVs interaction without validation. However, it appears from the comprehensive literature search that studies related to hybrid RESs integration are very rare and hence there is a need to develop this area.

This paper conducts extensive analysis and validation of wind-solar PV hybrid electricity system for typical household and application mini electric vehicle. The system is proposed to deliver smoother power to a typical household and electricity for charging the mini electric campus shuttle in the Central University of Kerala.

\subsection{Background and Context}

Decentralized renewable energy production is commonly the main solution to carbon emission in electricity generation. A decentralized or micro-electricity generation has the tendency of yielding significant benefits in terms of energy efficiency, reduction in carbon emission, mitigation to electricity transmission and distribution losses and enhancing energy security [37]. The term microgeneration is the generation of electricity in a reliable and environmentally sustainable way by individuals, small businesses, communities, etc. as an alternative to the grid-connected power [37, 38].

Transition from the current fossil-fuelled transportation and electricity generation to sustainable and green electricity in India requires the deployment of renewable energy technologies in the form of micro electricity generation. This involves the configuration of a diverse set of renewable energy technologies such as wind, solar PV, concentrated solar power, geothermal, renewable hybrid technologies, etc. for electricity generation and application to electric vehicles [39, 40].

India is among the countries with the largest energy production from renewable energy sources. This is because of several government initiatives and designed policies leading the country toward ambitious and largest renewable energy expansion capacity. Unfortunately, despite the massive penetration of renewable energies in the mix of electricity sources in India, more efforts are required from the Indian local and central governments.

The importance of this research and the obtained results lies in the necessity of identifying sustainable energy solution to the widespread electricity shortage at the study site. Certainly, the obtained results will serve as a benchmark toward achieving sustainable electricity and transportation in India at large. Based on the literature analysis, the methodology adopted in this study is first of its kind and is replicable in any location across the globe 


\section{MATERIALS AND METHODS}

\section{a) Meteorological Datasets}

This research utilized wind and solar meteorological datasets to investigate the potential of wind-solar PV hybrid electricity generation and to identify the viability of utilizing the technology for electric vehicles charging in Periye, Kasaragod using potential studies and validation. Periye is a town near Kasaragod city, the district headquarters of Kasaragod, Kerala, India. The town is situated within the Latitude of $12^{\circ} 43^{\prime}$ $87.51^{\prime \prime} \mathrm{N}$ and Longitude: $75^{\circ} 20^{\prime} 12^{\prime \prime} \mathrm{E}$, in the rich biodiversity of Western Ghats, sharing a border with the Arabian Sea by the west as shown in Fig. 1.

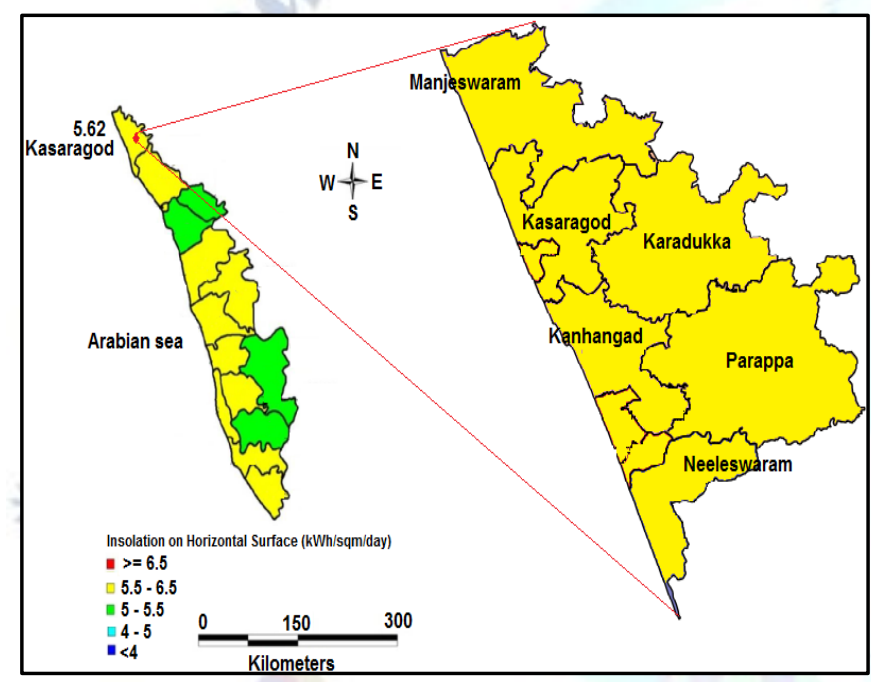

Fig 1. Geographic localization of Periye, Kasaragod

In the absence of any responsible agency for weather monitoring and forecasting at the study site, the study adopted PVGIS5 2006-2016 meteorological datasets recorded at $10 \mathrm{~m}$ above the ground with a resolution of $2 \times 2 \mathrm{~km}$, in understanding the long-term behaviour of the renewable energy resources at the study site. The study employed MATLAB-Simulink in extracting irradiation, wind speed, temperature, wind direction, and other required datasets. The extracted hourly datasets from PVGIS5 is grouped into seasons of the year winter (December, January, February), summer (March, April, May), monsoon (June, July, August, September) and post-monsoon (October, November) using MATLAB-Simulink.

The research adopted the datasets in identifying the potential of the hybrid wind/solar PV system for electricity generation for typical household electricity application and mini electric vehicle. To evaluate the performance of the system in the real-time situation, the validation studies of the system are conducted. The $1 \mathrm{~kW}$ HRES and the weather station are installed on the rooftop of Narmada building, Central University of Kerala. The output of the hybrid system is monitored through UNILOG-Pro differential input universal data logger for the period the experiment lasted.

\section{b) Meteorological Datasets Modelling 1. Wind Datasets and Wind Power Output Modelling}

The wind speed data is recorded at $10 \mathrm{~m}$ above the ground. However, since wind power depends directly on the cubic wind speed Eq. (1) and wind speed changes with height in the boundary layer (wind shear), it is, therefore, necessary to scale the wind speed data to the required hub height of the selected wind turbine.

In this regard, the power-law (Eq. 2), is the common model adopted by several studies reviewed in the literature despite been prone to several limitations that can promote errors in the estimation of wind speed at hub height $[41,42]$. In the power-law model, the exponent $(\alpha)$ is an empirically derived coefficient that varies with height and atmospheric stability. In most cases, studies in the literature often assigned a constant value of $(\alpha)$ approximately $1 / 7$ or 0.143 even under calm and neutral stability conditions. This can sensibly compromise the model performance by generating incoherent and irregular data that can lead to overestimation or underestimation of the wind resources.

To address this challenging issue, this study adopted Millward-Hopkins model Eq. 3 in extrapolating the wind speed from the reference height to the hub height suitable for the selected wind turbine. Millward-Hopkins takes accounts of several boundary layer terms, which makes it on average a more realistic model compared to other models designed for this application [43-46].

\section{Where,}

$$
1 / 2 \rho \eta \mathrm{C}_{\mathrm{p}} \mathrm{AV}^{3}(1)
$$

$\rho=$ density of air $(\mathrm{kgm}-3), \mathrm{V}=$ wind speed $\left(\mathrm{ms}^{-1}\right)$, $\mathrm{Cp}=$ Coefficient of Performance $\eta=$ gearbox efficiency and generator efficiency $\mathrm{A}=$ area of the wind turbine blades $\left(\mathrm{m}^{2}\right)$

$$
\mathrm{V}=\mathrm{V}_{0}\left(Z / Z_{0}\right)^{\alpha}(2)
$$

Where,

$\mathrm{V}=$ Wind speed at hub height $\mathrm{Z}$ in $\mathrm{ms}-1$, V0 = Wind speed at reference height Z0, $\quad \alpha=$ Wind shear exponent coefficient which varies from 
site to site.

$$
\mathrm{V}_{\text {hub }}=\mathrm{V}_{\text {ref }} \frac{\ln \left(\mathrm{Z}_{\text {hub }} / \mathrm{Z}_{0-\text { ref }}\right)}{\ln \left(\left(10 / \mathrm{Z}_{0-\text { ref })}\right.\right.}(3)
$$

Where,

$\mathrm{V}_{\text {hub }}=$ Wind Speed at hub height $\mathrm{V}_{\text {ref }}=$ Wind Speed at reference height $=10 \mathrm{~m} \quad Z_{\mathrm{hub}}=$ Reference height $Z_{0-\text { ref }}=$ Reference height roughness length.

The cubic spline interpolation is employed in modelling the performance of the selected WECs based on the available wind resources. The best polynomials for the spline are identified using the curve-fitting tool of MATLAB Simulink.

\section{Insolation and Solar Power Output Modelling}

Starting with the extracted solar irradiance and the solar module parameters given in Table 2, the solar PV power output is estimated using the global benchmark model for estimating the photovoltaic system electricity output given in Eq. 4.

$$
E=A r G_{i} P R \quad \text { (4) }
$$

Where,

$\mathrm{E}=$ Energy Output $(\mathrm{W}), \mathrm{A}=$ Total solar panel Area $\left(\mathrm{m}^{2}\right), \mathrm{r}=$ solar panel yield $(\%), \mathrm{G}_{\mathrm{i}}=$ Global Horizontal Irradiance, $\mathrm{PR}=$ Performance ratio

The Performance Ratio (PR) is a very essential value for evaluating the quality of PV installation independent of the orientation or inclination of the panel i.e. it is taking account of all system loses.

It is important to highlight the uniqueness of this research in taking account of the solar PV module operating temperature $\mathrm{T}_{\text {mod }}$. The most recent literature on HRES is not taking account of this important parameter in solar PV electricity generation. The module operating temperature $\mathrm{T}_{\text {mod }}$ is calculated using Eq. 5 with the aid of the ambient temperature $\mathrm{T}_{\mathrm{amb}}$ and Global Horizontal Irradiance $\mathrm{G}_{i}$.

It is important to point that the model does not take into account, the cooling advantage of the wind on the PV modules. This cooling from wind passing below the PV system can increase the efficiency of the solar PV system in the range of $0-7 \%$ depending on the wind strength at the site as reported in Koehl et al. [48]; Schwingshackl et al. [49] and Huld et al. [50].

$$
T_{\text {mod }}=T_{a m b}+0.035 G_{i}(5)
$$

\section{Where}

$\mathrm{T}_{\text {mod }}=$ Module operating temperature $\mathrm{T}_{\mathrm{amb}}=$ Ambient temperature $\mathrm{G}_{\mathrm{i}}=$ Global Horizontal Irradiance.

\section{c) Load Assessment}

Electricity demand data is one of the stochastic parameters required in the designing of any successful HRES.

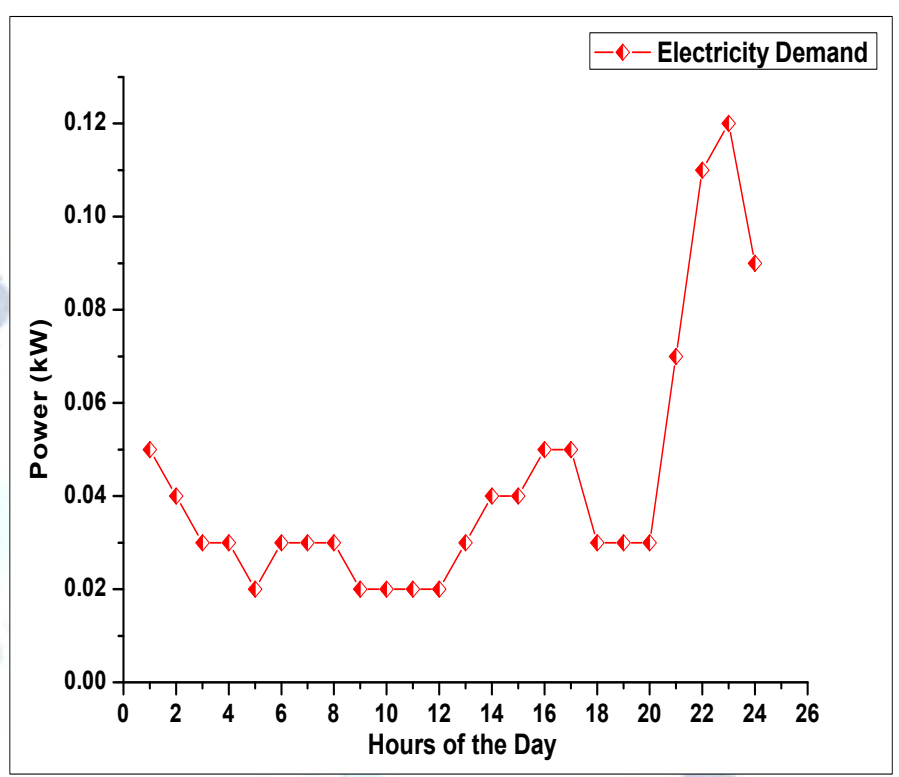

Fig. 2: Typical household electricity demand profile

Unfortunately, the hourly electricity profile of a typical household in countries like India is very difficult because of the erratic nature of electricity supply across the counties. Methodologies recently discovered in the literature for generating a typical household electricity demand profile includes, interpolation method Gado et al. [51], Artificial Neural Networks (ANN) Gajowniczek and Zabkowski [52], non-linear and multiple regression methods [53, 54] and genetic algorithm Ozturk et al. [55]. It is very clear that those modelling approaches when utilized in locations with intermittent power supply, the methods will certainly generate incoherent data. This article introduces the PVGIS electricity demand profile depicted Fig. 2, based on the consumption of all the electrical appliances connected to a load of a typical household during 24-hours of the day with most of the consumption during morning and evening hours.

\section{d) HRES Components}

To achieve the objectives of this study, four major components are considered in the modelling, analysis and validation of the designed HRES. The components include 400W Wind Energy Conversion system (WECs), 600Wp solar PV system, Battery Energy Storage System (BESS) and BSC-P1 electric campus shuttle as depicted in Fig 3. As shown in the figure, connected to the DC bus is WECs, the solar PV system and the BESS. The 
typical household electricity load and the Electric Vehicle Supply Equipment (EVSE) are connected to the AC bus through DC-AC converter.

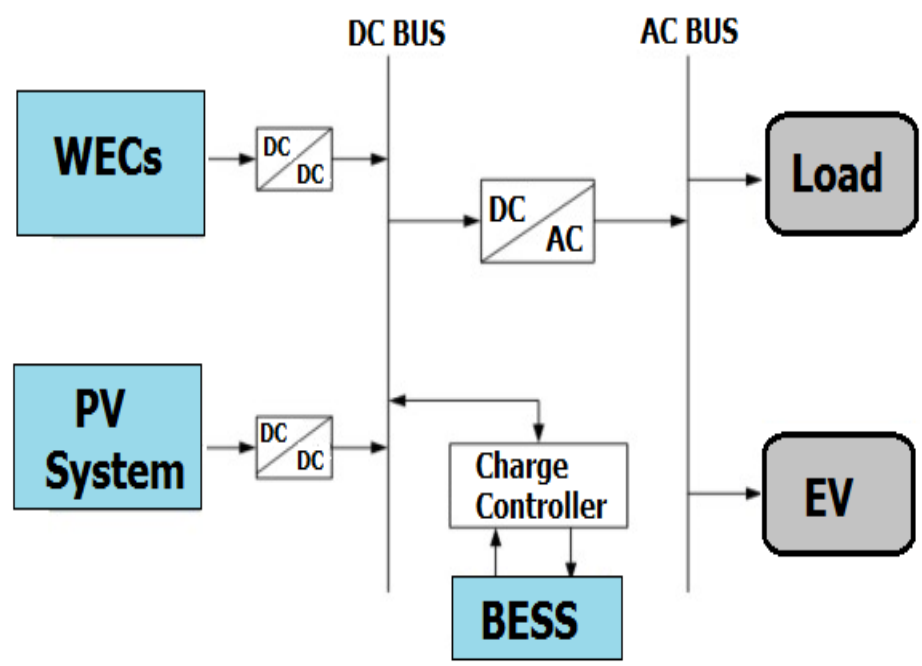

Fig. 3: Configuration and components of the proposed HRES.

The proposed HRES system caters to the load demand of typical household and the EV, but when there is excess power from the HRES, the excess power is used to charge the BESS.

\section{Solar PV modules}

Table 1 tabulates the specifications and parameters of the 600Wp solar PV system at Standard Test Condition (STC). The position of the study site falls in the region of the Northern hemisphere, which requires an optimal angle of $0^{\circ}$ (azimuth $0^{\circ}$ ). Based on the model calculations, $25^{\circ}$ (i.e. $25^{0}$ azimuth $0^{\circ}$ ) appear the best tilt angle for the solar panel to receive maximum solar radiation.

\section{Wind Energy Conversion System (WECS)}

Eco-Worthy 400W horizontal axis wind turbine technical parameters tabulated in Table 2 and the power curve depicted in Fig. 4 is adopted in modelling the wind power output based on the wind datasets for the potential studies and validation. The WECs have an efficient rotor design and can operate at low wind speeds with high efficiency and longevity. This makes it reliable for both on-grid and off-grid applications.

\section{The Electric Vehicle (EV)}

BSC-P1 mini electric vehicle with the specifications given in Table 3 is adopted in identifying the performance of the hybrid system in electric vehicle charging. The selected electric vehicle has electricity demand of $0.8 \mathrm{~kW}$ for charging the five (5) $12 \mathrm{~V} / 38 \mathrm{Ah}$ lead-acid batteries delivering power to the brushless DC motor for the vehicle propulsion.
BSC-P1 has simple, dynamic and elegance appearance in addition to its convenient operation. The EV operates with fast charging mode from the Electric Vehicle Supply Equipment (EVSE) operating at $220 \mathrm{~V}$ on $50 \mathrm{~Hz}$ frequency. According to the standards, EVSE charging three classes are identified as level 1, level 2 and DC Fast Charge (DCFC) [58]. The BSC-P1 is equipped with level 2 charging classification using $220 \mathrm{~V}$ AC.

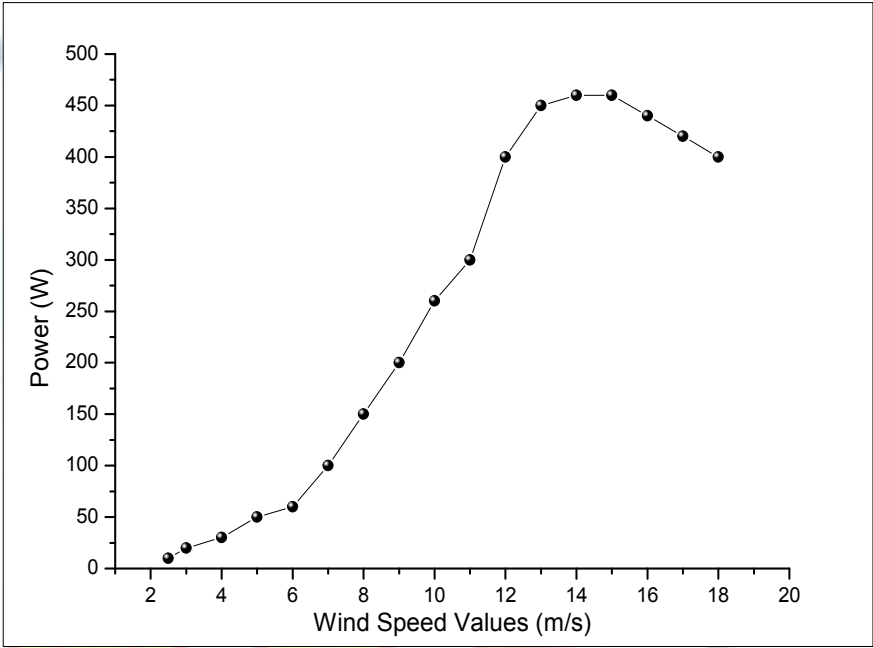

Fig. 4: Eco-Worthy 400W Manufacturer Curve.

Table 1: Technical parameters of the solar PV system at STC[47]

\begin{tabular}{ll}
\hline Parameter & Value \\
\hline Nominal power $\left(\mathrm{P}_{\max }\right)$ & 150 \\
Panel area $\left(\mathrm{m}^{2}\right)$ & 0.98 \\
Operating Voltage $(\mathrm{V})$ & 12 \\
Short-circuit current Isc $(\mathrm{A})$ & 8.80 \\
Voltage at maximum power $\mathrm{V}_{\mathrm{MPP}}(\mathrm{V})$ & 18.25 \\
Maximum power current $\mathrm{IMPP}_{\mathrm{MP}}(\mathrm{A})$ & 8.22 \\
Module efficiency $(\mathrm{\eta} \%)$ & 15.90 \\
Power tolerance $(\mathrm{W})$ & $0 \sim+5$ \\
Operating temperature range $\left({ }^{\circ} \mathrm{C}\right)$ & -40 and +85 \\
\hline
\end{tabular}

Battery Energy Storage System (BESS) and Inverter.

The generic model of rechargeable battery depicted in Fig. 5 is adopted in modelling the battery storage system. The BESS is modelled using Eq. 6 and Eq. 7, which are similar to the model adopted in the study conducted by Tremblay et al. [59], and Krishan and Suhag [60]. 
Table 2: Technical parameters of the WECs [56].

\begin{tabular}{ll}
\hline Parameter & Value \\
\hline Turbine type & HAWT \\
Rotor diameter & $1.2 \mathrm{~m}$ \\
Nominal Power Output & $400 \mathrm{~W}$ \\
Power Coefficient $\left(\mathrm{C}_{\mathrm{p}}\right)$ & 0.42 \\
Cut-in Wind Speed & $2.5 \mathrm{~ms}^{-1}$ \\
Survival wind speed: & $35 \mathrm{~ms}^{-1}$ \\
Rated Wind Speed & $10.5 \mathrm{~ms}^{-1}$ \\
Rated Voltage & DC: $12-24 \mathrm{~V}$ \\
Rated Rotate Speed & $800 \mathrm{r} / \mathrm{min}^{-}$ \\
\hline
\end{tabular}

This model helps in identifying the suitable BESS for the validation studies and suitable Watt-hour capacity required for the typical household application during non-generation hours from the RESs. The BESS is utilised primarily in the HRES designs to ensure smooth and stable power supply in the event of a mismatch between the RESs generation and demand.

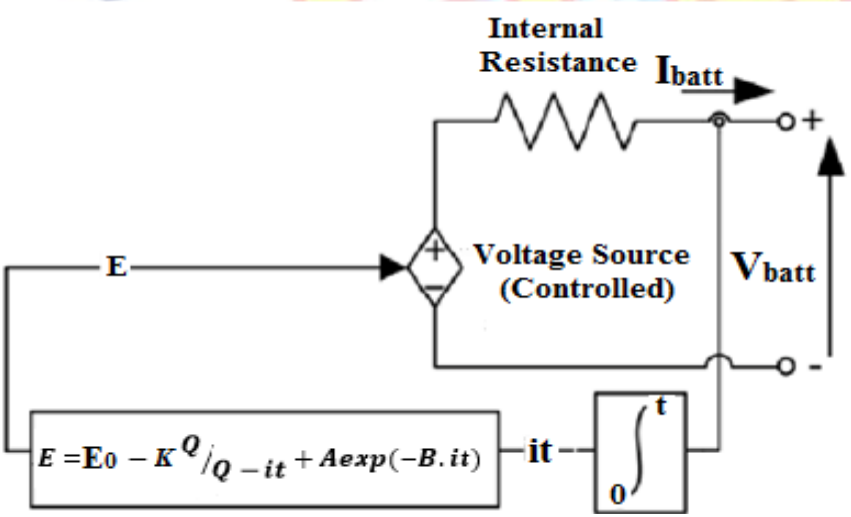

Fig. 5: Generic model of rechargeable battery

Luminous solar nxg 1400-12V hybrid inverter shown in Table 4 is utilised in the validation studies.

$$
E=E_{0}-K^{Q} / Q-\int i d t+A \exp \left(-B \int i d t\right)(6)
$$

Where,

$\mathrm{E}=$ Controlled voltage source $(\mathrm{V}), \mathrm{E}_{0}=$ Constant voltage $(\mathrm{V}), \mathrm{K}=$ Polarization constant $(\mathrm{V} / \mathrm{Ah}), \mathrm{Q}=$ Maximum ampere-hour capacity of the battery (Ah), $\int \mathrm{idt}=$ Charge taken/delivered by the battery (Ah), $A=$ Exponential voltage $(\mathrm{V}), B=$ Exponential capacity $\left(\mathrm{Ah}^{-1}\right), \mathrm{V}_{\text {batt }}=$ Battery nominal voltage $(\mathrm{V})$, $\mathrm{R}_{\text {batt }}=$ Internal resistance $(\Omega)$, $\mathrm{I}_{\text {batt }}=$ Battery current (A).
Based on the modelling, two (2) Luminous ILTT 26060-220Ah, $12 \mathrm{~V}$ were identified to be suitable for the validation studies.

$$
\mathrm{C}_{\mathrm{Wh}}=\left(\mathrm{E}_{\mathrm{L}} / \mathrm{AD}\right) /\left(\eta_{\text {batt }} . \mathrm{t} . \mathrm{DoD}\right)
$$

Where,

$\mathrm{EL}=$ the average daily load energy $\left(\mathrm{kWh}_{\text {day }}{ }^{-1}\right), \mathrm{AD}=$ Daily autonomy of the battery, $\mathrm{DoD}=$ Battery depth of discharge, $\eta_{\text {Batt }},=$ efficiency

\section{Results AND Discussion}

\section{A. Monthly Wind Speed, Irradiation and} Monthly Power Output Analysis

The extracted wind speed data measured at $10 \mathrm{~m}$ varies between $0.15 \mathrm{~ms}^{-1}$ to $7.75 \mathrm{~ms}^{-1}$ with an annual average hourly value of $2.82 \mathrm{~ms}^{-1}$. This shows that the site has reasonable wind resources for small scale, medium and large-scale wind electricity generation.

Certainly, the Millward-Hopkins model adopted in scaling the wind speed data from reference height to the required hub height has shown best accuracy in comparison to the most common model in the literature (power-law) as depicted in Fig. 6. Results from the figure show that at all levels, the wind speed values underestimated by the power-law model.

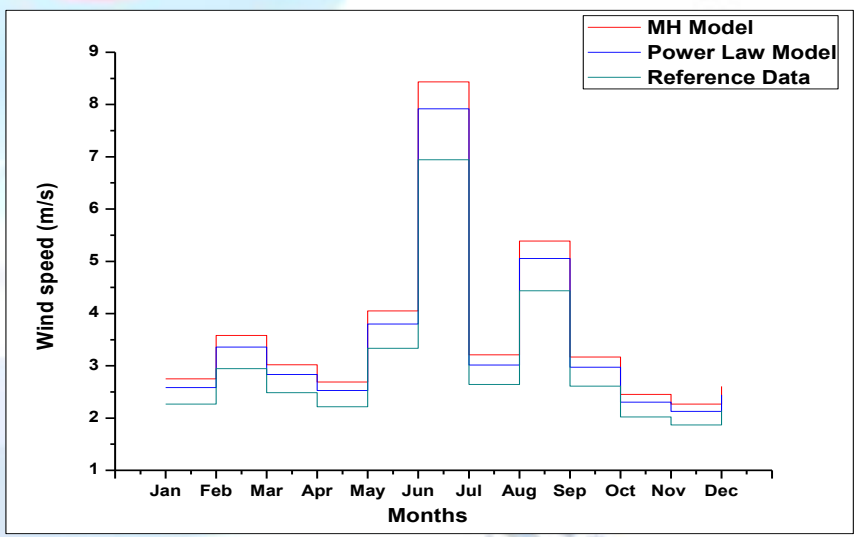

Fig. 6: Comparison between Millward-Hopkins and Power law.

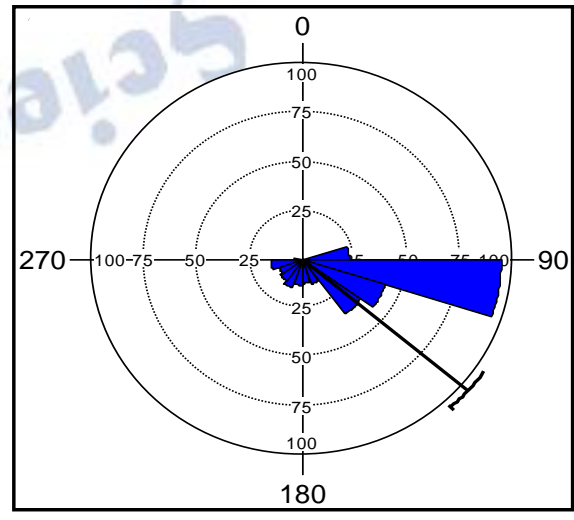

(a) 

Wind-Solar PV Hybrid Electricity Generation and Application to Electric Vehicle"

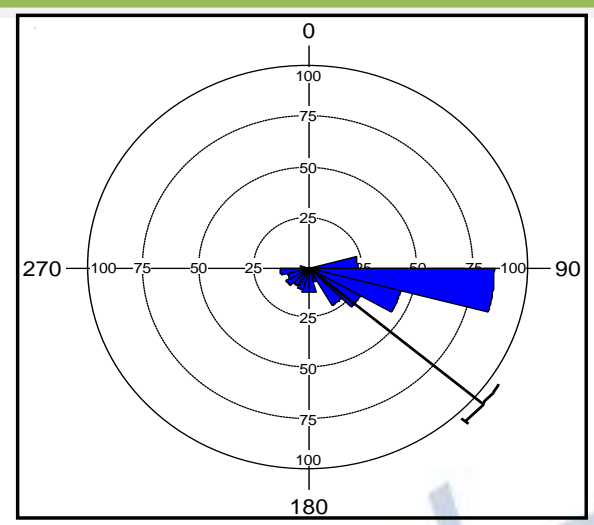

(b)

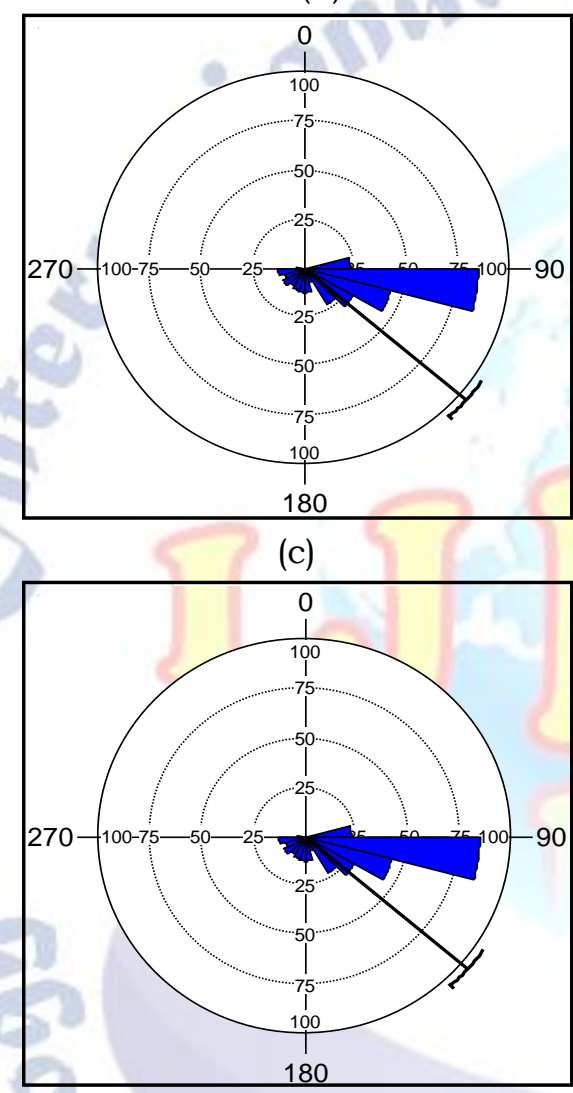

(d)

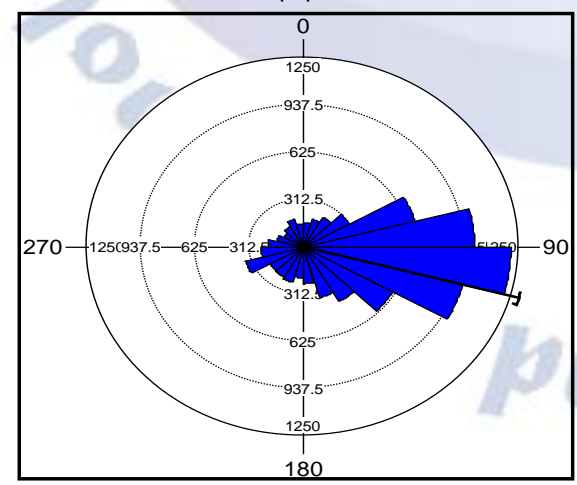

(e)

Fig. 7. The wind rose diagram: a) Winter; b) Summer; c) Monsoon;d) Post-monsoon; e) typical year

Electric Vehicle Specifications [57]

Table 4:

Luminous solar nxg hybrid inverter $1400-12 \mathrm{~V}$

\begin{tabular}{ll}
\hline Parameter & Value \\
\hline Input Voltage (eco mode) (V) & $100-290$ \\
Output Frequency (Hz) & $50+/-2$ \\
Output Voltage (V) & $220-230$ \\
Rated AC power (VA, V) & 1100,12 \\
Inverter efficiency ( $\mathrm{y} \%)$ & 94.1 \\
Wave Type & Pure Sine Wave \\
Charge Controller Rating (A/V) & $40 / 12$ \\
\hline
\end{tabular}

\begin{tabular}{ll}
\hline & \\
\hline Parameter & Value \\
\hline Power & $800 \mathrm{~W}$ \\
Power supply & Lead Battery \\
Battery & $12 \mathrm{~V} / 38 \mathrm{Ah}$ \\
Voltage & $\mathrm{DC} / 60 \mathrm{~V}$ \\
Top speed & $40-45 \mathrm{kmh}^{-1}$ \\
Mileage & $120 \mathrm{~km}$ \\
Full charge time & $6 \sim 10 \mathrm{hours}$ \\
Motor & Brushless motor \\
Load Capacity & $400 \mathrm{~kg}$ \\
Net weight & $350 \mathrm{Kg}$ (with battery) \\
\hline
\end{tabular}

Fig. 7 shows the analysis of the wind direction using the wind rose method from the extracted data. The wind rose generated for all the seasons of the year, revealed that the predominant wind direction at the site is ESE (East South East) direction across all the seasons of the year. This is an indication of stable weather conditions at the study site.

The monthly average irradiance of the extracted data has a mean monthly value of $463.04 \mathrm{Wm}^{-2}$ that varies between $351.75-588.88 \mathrm{Wm}^{-2}$. The analysis of temperature at the study site revealed

the mean monthly air temperature of $27.19^{\circ} \mathrm{C}$ with the highest value of $29.72^{\circ} \mathrm{C}$ in April, and the corresponding lowest value of $26.28^{\circ} \mathrm{C}$ in September. The average temperature observed corresponds to $48^{\circ} \mathrm{C}$ module operating which is within the range of the NOCT (Nominal Operating Cell Temperature) of the selected solar PV system for simulation and validation studies.

The mean monthly analysis of the wind speed at $15 \mathrm{~m}$ and solar resources are presented in Fig. 8a. By analyzing the figure, it appears that June has the highest monthly mean wind speed and November has the lowest wind speed value and 
power output.As it is explicitly evident from the trends in Fig. 8a, March has the highest irradiation and the lowest irradiation values are recorded in June. The analysis of temperature revealed the mean monthly air temperature of $27.19^{\circ} \mathrm{C}$ with the highest value of $29.72^{\circ} \mathrm{C}$ in April, and the corresponding lowest value $26.28^{\circ} \mathrm{C}$ in September as shown in Fig. 8b.
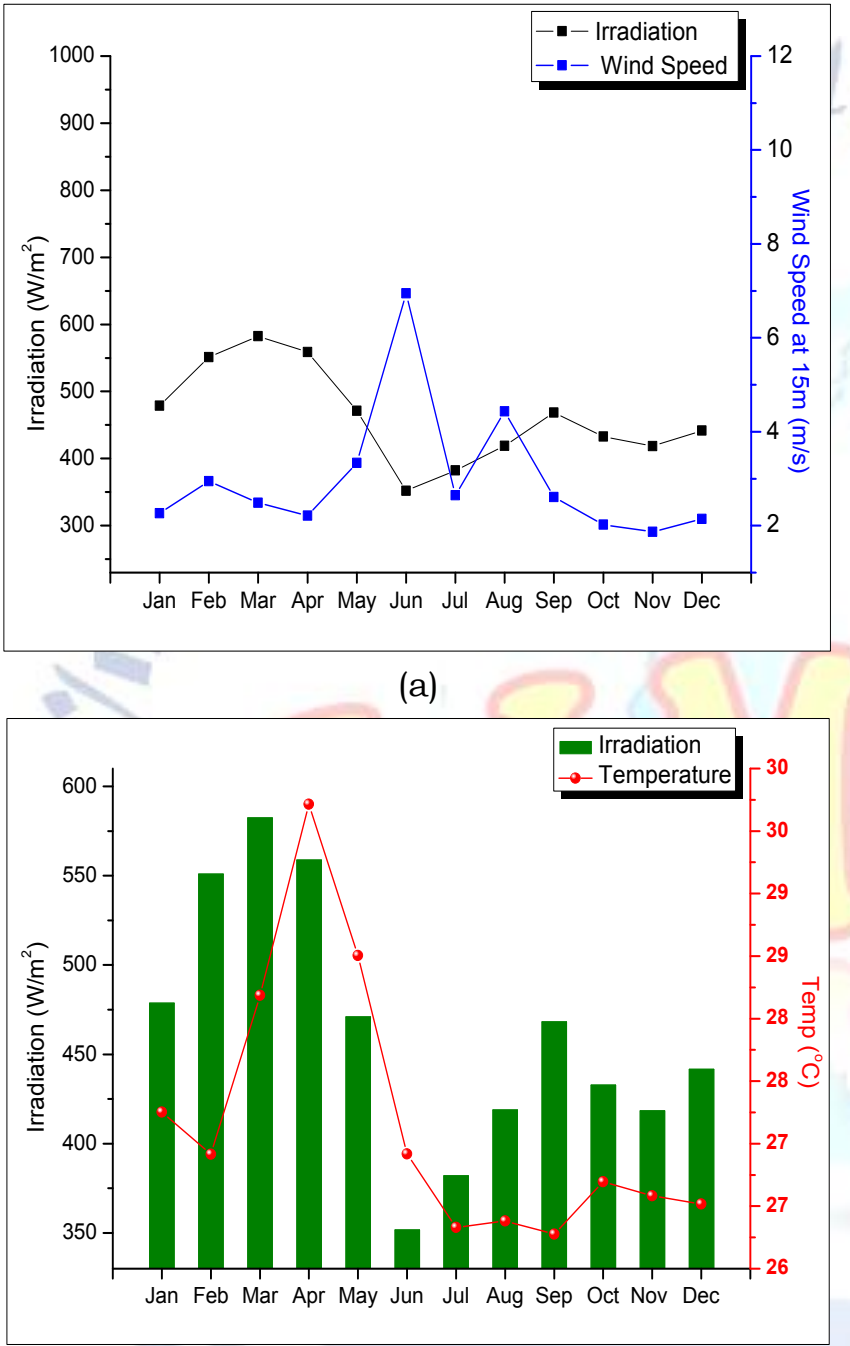

(b)

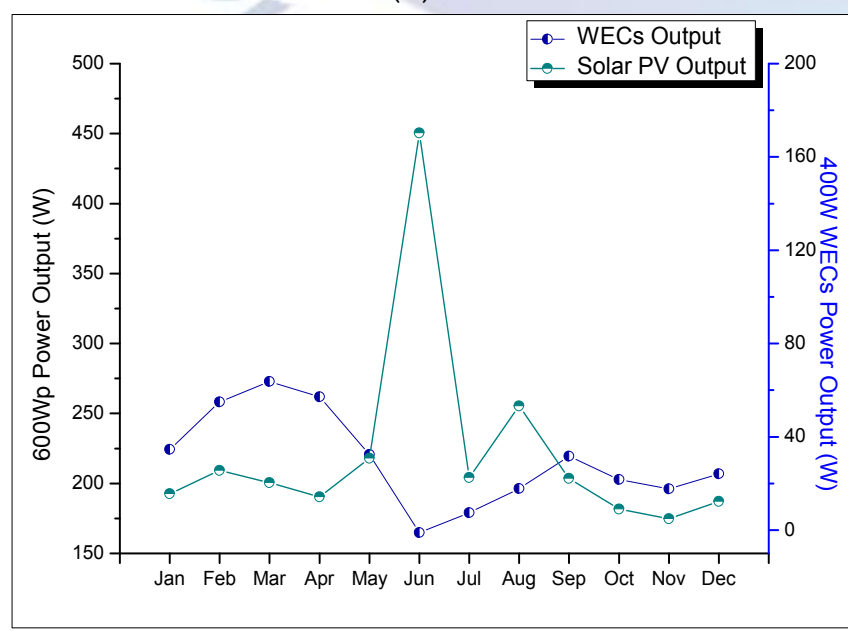

(c)

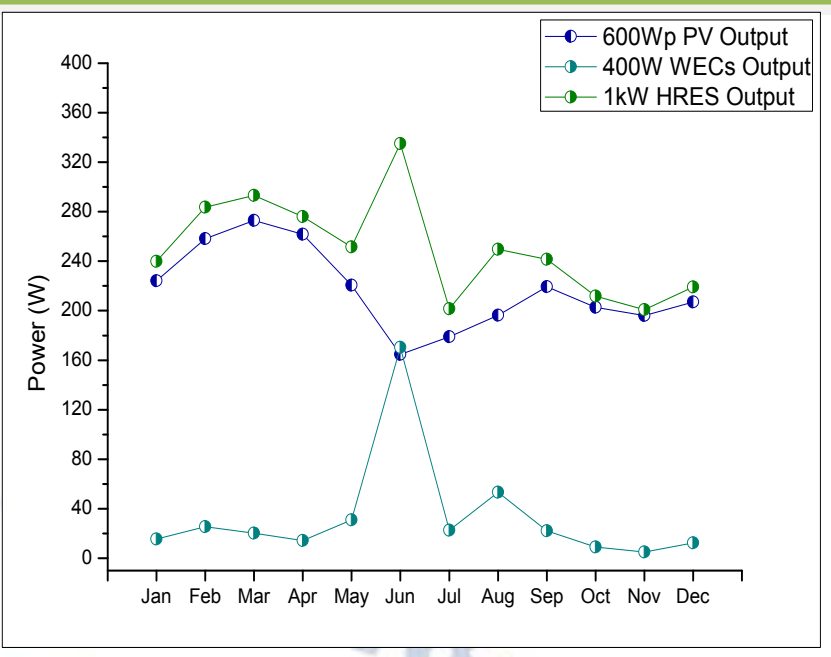

(d)

Fig. 8. Monthly analysis: a) mean wind speed at $15 \mathrm{~m}$ and monthly irradiation: b) Global Horizontal Irradiation and air temperature: c) mean monthly power output: d) mean monthly hybrid power output

Observation of the results in Fig. 8c, on the generated wind power output by the proposed cubic spline interpolation model, shows that there is no reduction on the power rating of the wind generator at all levels of wind speed. This means the model is compatible with the original values in the turbine power curve. Although techniques such as Gamma, Lognormal, three-parameter Beta, Rayleigh and Weibull distributions are successfully used by different studies, the spline interpolation method often performs best in diurnal wind resources analysis. Thapar et al. [61], Lydia et al. [62] and Said et al. [16] highlighted that the cubic spline interpolation method is often preferred over other interpolation because the interpolation error can be made small, even when using low degree polynomials for the spline. Additionally, by applying the benchmark model on the monthly irradiation data, the results derived shows the effectiveness of the model in estimating solar power output as shown in Fig. 8c.

It is evident from the observed trends in the figure that the distinctive profile of the wind and solar resources across the study site. This shows that the combination of the two renewable energy systems in the form of hybrid, can offer a unique opportunity for the elimination of intermittency effect as depicted in Fig.8d. This analysis is presented in this section for better observation of how the wind and solar resources are correlated every month. This will surely portray clear information about the potential of the HRES in electricity generation in the study area. 


\section{B. Seasonal Resources and Power Output Analysis}

Seasonal renewable energy resources analysis is paramount in any finest renewable energy potential studies. The irradiation and wind speed across the typical day in all the seasons of the year are shown in Fig. 9. The results from the figures revealed a clear pattern of high values during the peak sunshine hours for the solar irradiation and the wind speed. This is among the most interesting findings of this research because it gives a clear relationship between the two renewable energy resources. Generally, the observed wind speed values across the study area show a clear pattern of higher wind speeds during the sunshine hours when compared with night hours. This is not a complex issue, because the higher wind speed during the peak sunshine hours can be because of uneven heating of the earth by the sun. The heating causes buoyancy that is leading to circulation and movement of air parcels from the region of higher pressure to the region of the lower pressure of the earth. This is the driving factor for wind energy formation showing that wind energy depends heavily on solar radiation Gado et al. [51]; Graham [63]; Azad et al. [64]; Muthukumar Muthuchamy et al. [65]; Nelson et al. [66]. The clear results presented on the relationship between wind and solar energy resource can be attached to the efforts made in undergoing the diurnal analysis of the resources at all levels. This shows that a huge benefit can be achieved by hybridising the two renewable energy sources in electricity generation.

To appreciate the level of the huge potential of RESs in electricity generation in the study area, Fig. 10 depicted the overall seasonal analysis of the $1 \mathrm{~kW}$ wind-solar PV hybrid system. As highlighted, the system comprises 600Wp solar PV system and 400W Wind Energy Conversion system (WECs). Clear observations of the trends in the figure will reveal that due to higher solar PV output from the system, the hybrid output contour follows the solar PV output contour. The main observation is drawn from the results in Fig. 10 is that the study area is a very good location for solar PV electricity generation. Additionally, based on the observed potential of RESs hybrid system can be a viable solution to the ever-increasing electricity shortage across the Kasaragod district where the study site is situated.

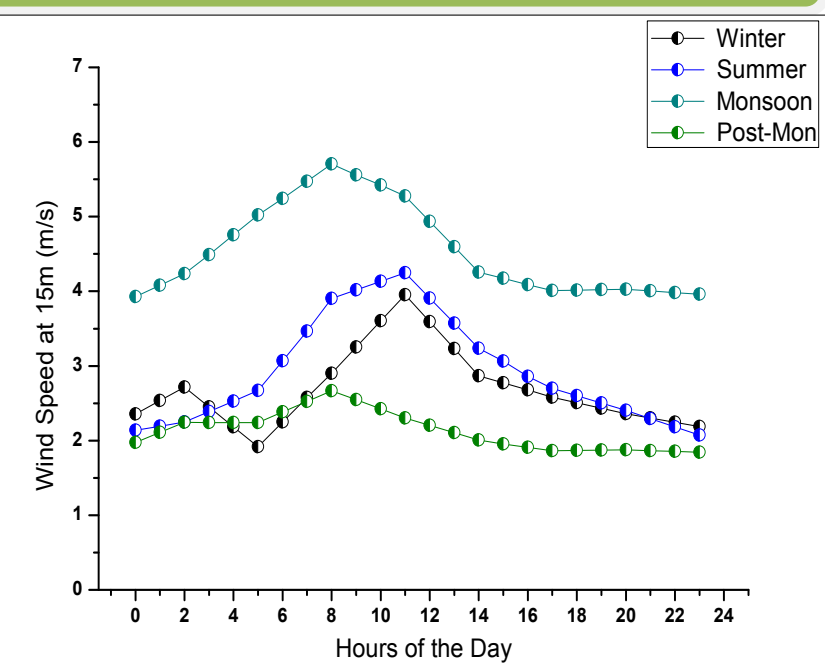

(a)

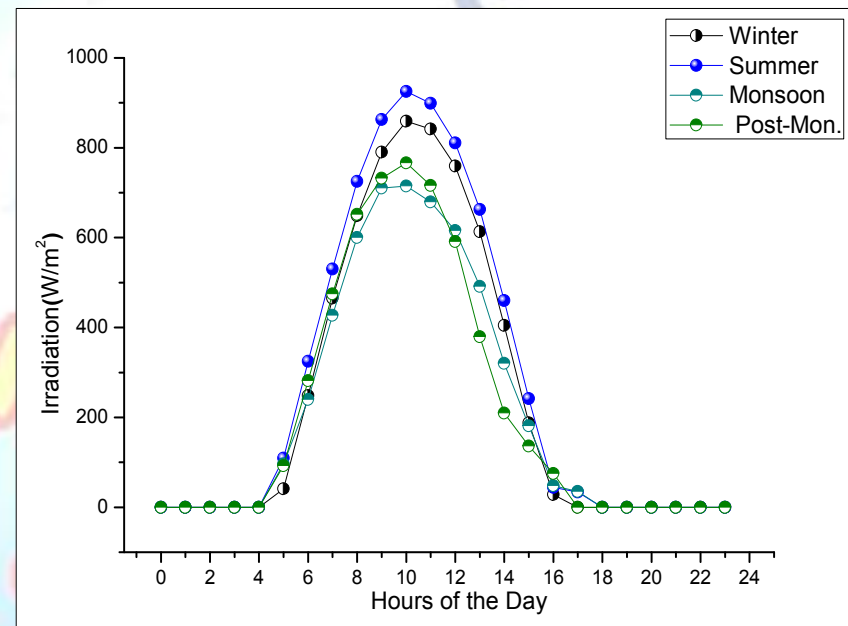

(b)

Fig. 9. Diurnal seasonal variation; (a) wind speed at $15 \mathrm{~m}$; (b) irradiation

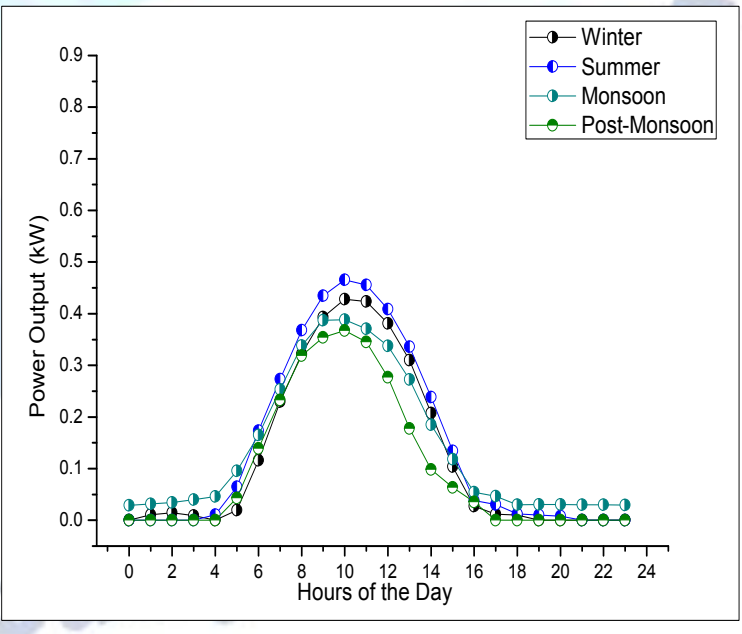

Fig. 10. Seasonal 1kW wind-solar PV hybrid power output 


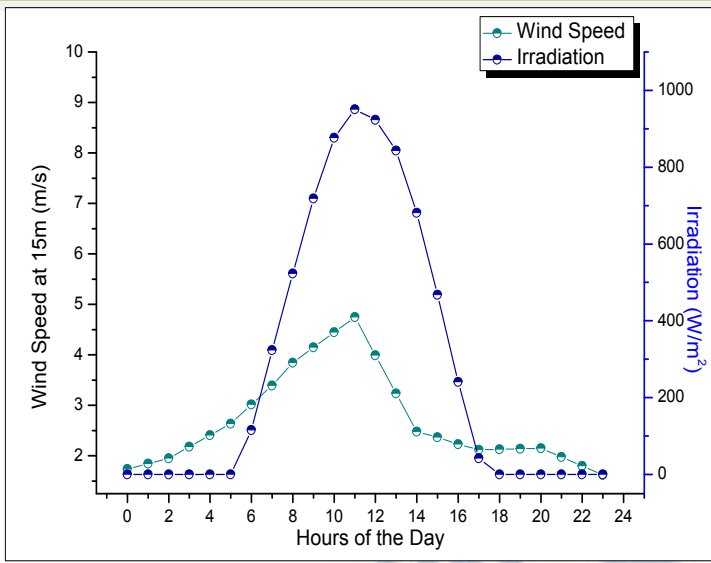

(a)

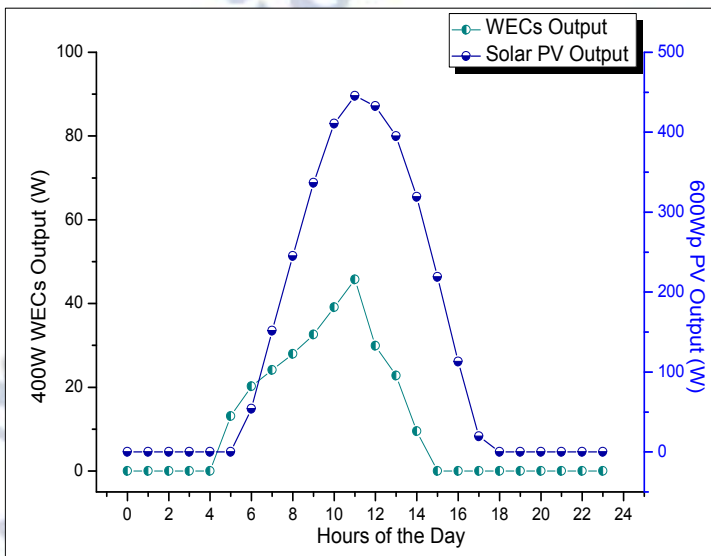

(b)

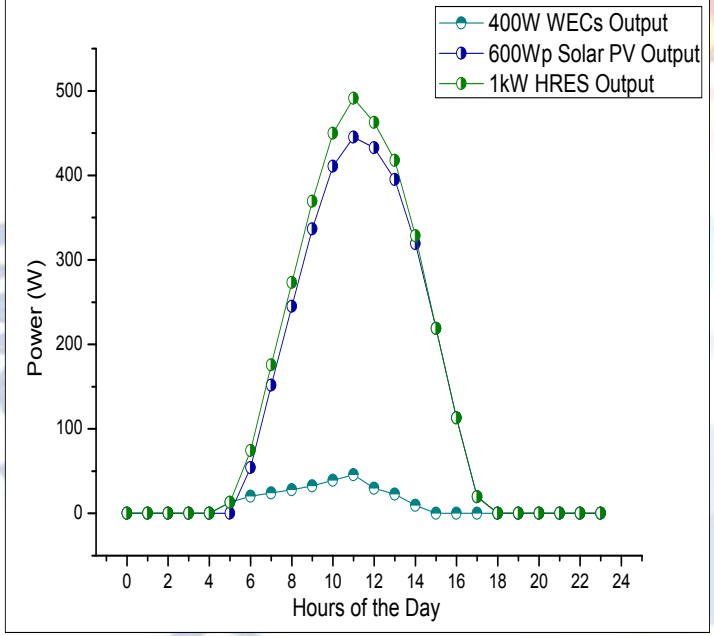

(c)

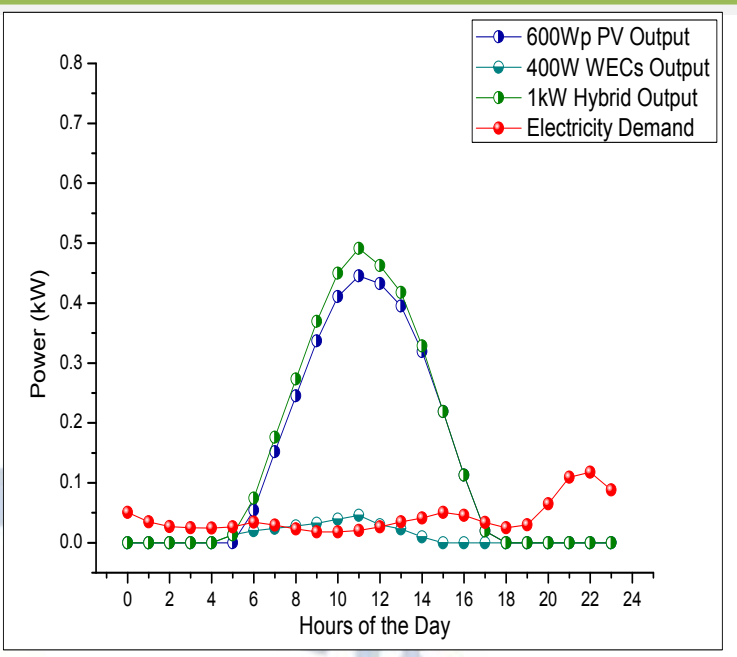

(d)

Fig. 11. Typical day across all the seasons a) wind speed at $15 \mathrm{~m}$ and irradiation: b) power output (c) HRES power output (d) HRES performance against typical household electricity demand

\section{Hybrid system Performance Analysis}

Diurnal renewable resources' modelling is among the technique that can provide clear information on the stochastic and dynamic nature of renewable resources in renewable electricity

generation and forecasting. The relationship between the diurnal wind speed at $15 \mathrm{~m}$ and irradiation across the typical day across all the seasons are presented in Fig. 11a.

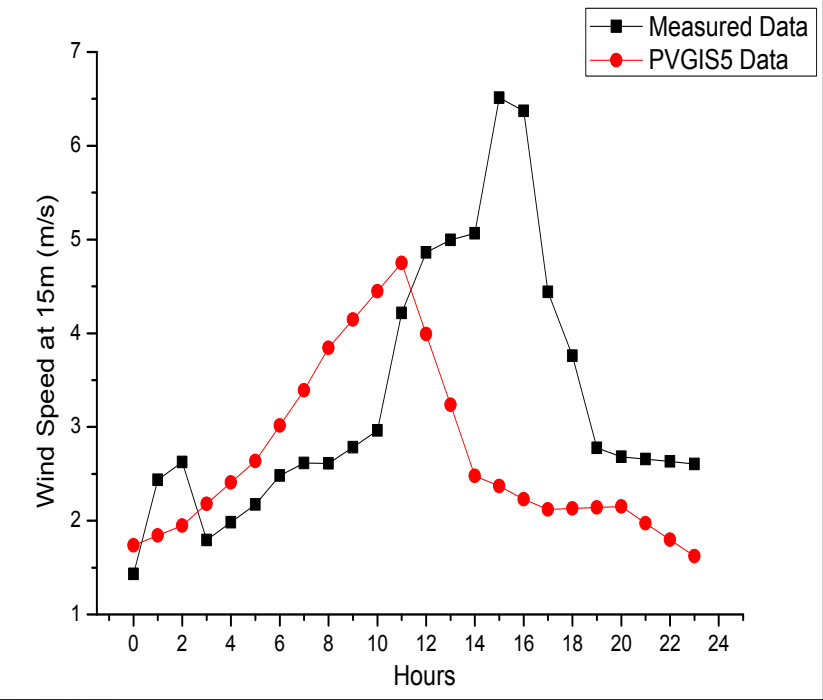

(a) 


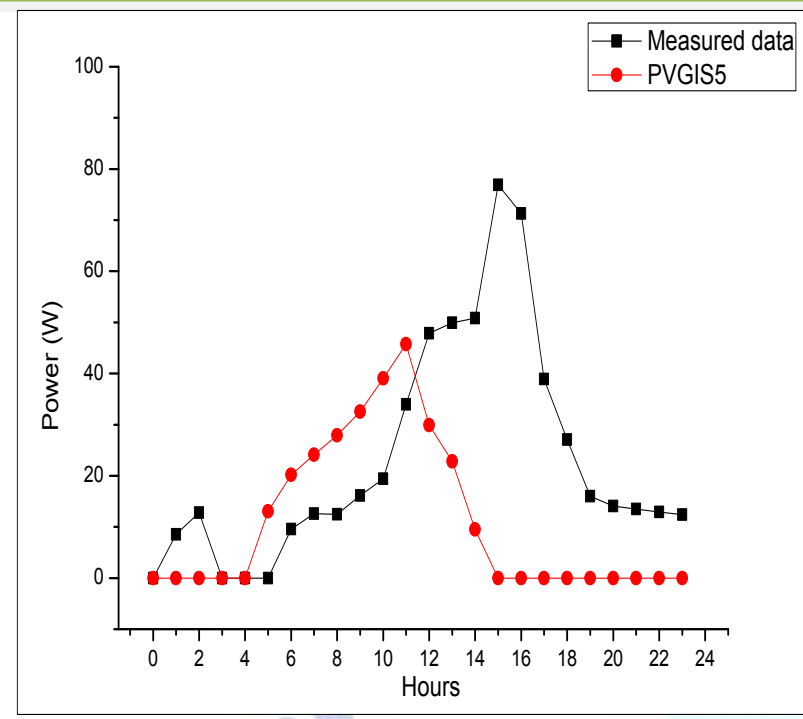

(b)

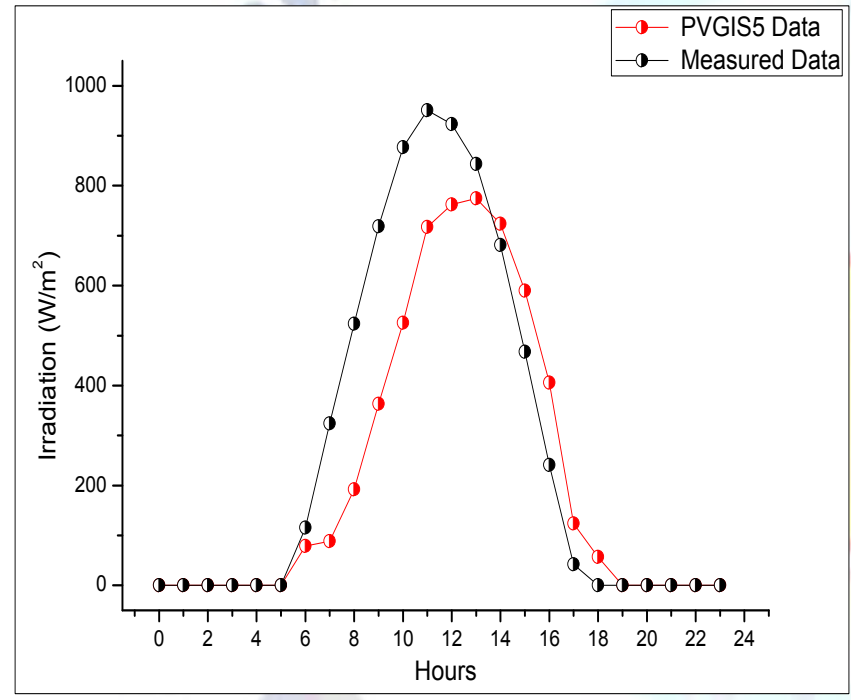

(c)

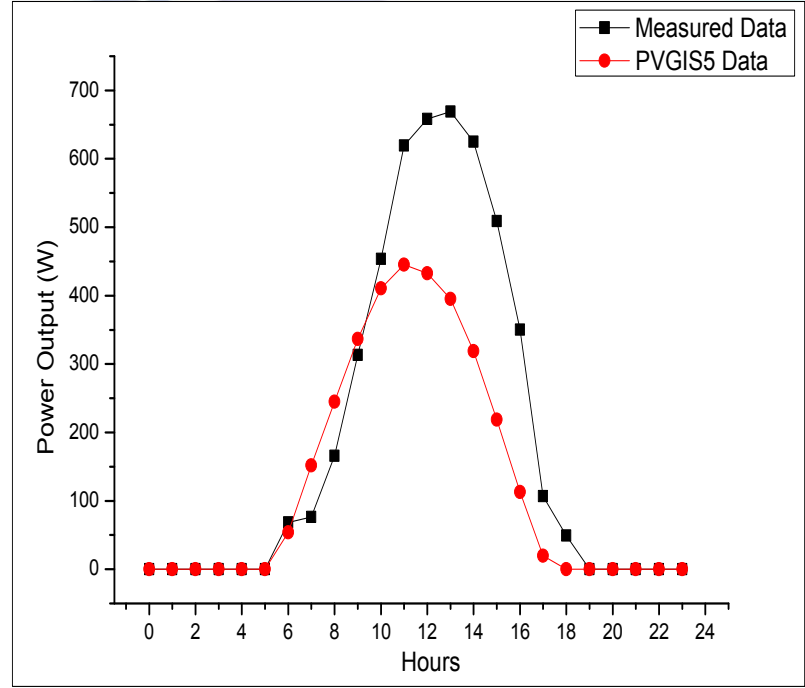

(d)

Fig. 12. Comparison of PVGIS5 and real parameters: a) Wind speed at $15 \mathrm{~m}$; b) $400 \mathrm{~W}$ WECS power output; c) Irradiation; d) $600 \mathrm{Wp}$ solar PV power output

Evidence from the figure shows a clear pattern of high irradiation values during the peak sunshine hour. Because of the direct relationship between solar energy and wind energy, higher wind speed values and WECs power output are also recorded during the peak sunshine hours as depicted in Fig. $11 \mathrm{~b}$. The trend in Fig. 11c summarized the huge benefits of hybridizing the two RESs in electricity generation. Although, it is clear that solar PV power output outweighs the WECs power output, hybridizing the two RESs can offer a higher chance of eliminating intermittency effect of RESs in electricity generation.

The overall performance of the hybrid system is tested against the typical household electricity demand to understand the performance of the system. The result in Fig. 11d depicts the hourly power output from the 400W WECs, 600Wp solar PV, 1kW HRES and the typical household hourly electricity demand during a typical day across all the seasons. It is evident from the trends that, there is higher power output from the solar PV system and wind turbine during peak sunshine hours. It also clear from the results that, during the sunshine hours, the solar PV and wind power outputs exceeded the electricity demand and hence, the hybrid output exceeded the demand greatly. Although the main issue about BESS is the cost because it can significantly increase the overall cost of the system. However, based on the results observed on the HRES performance, the payback period of the system is optimistically low because of the availability of the renewable resources across the study sites especially the solar resources.

\section{HRES Performance Validation}

To evaluate the real performance of the designed HRES, the finest real-time validation of the system is conducted. The $1 \mathrm{~kW}$ hybrid system and the weather station are installed at the rooftop of Narmada building, Central University of Kerala.The output of the hybrid system is monitored through UNILOG-Pro differential input universal data logger.To describe more precisely the variation of the two data sources,statistical analysis was conducted to understandthe variation between the real parameters and the estimated parameters, the results are tabulated in Table 5 . The relationship between the measured wind speed at $15 \mathrm{~m}$, irradiation and corresponding power outputs against the PVGIS5 wind speed values at $15 \mathrm{~m}$ and measured irradiation corresponding power outputs are depicted in Fig. 12. It is evident 
from the results in Fig. 12 and Table 5 that the obtained results from the simulations and the experimental measurements are acceptable as they mainly agree with the experimental results. Although the trends of the two data sources look similar in nature, the measured data shows better accuracy. Additionally, as admitted, in most HRES case studies, the simulated results usually appear higher than the experimental results. The results observed in this study contradict the results of many studies in the literature because the measured parameters are higher than the simulated results in all cases. The trends observed in this section are similar to the results reported by Mustafa [67]; Sami and Icaza [68] and Lennart et al. [69]. It is clear from both the simulation and validation results that there is a clear correlation between wind speed and irradiation. Although there are several metrological parameters governing the movement of air parcels in the atmosphere, the buoyancy effects due to temperature increase are concluded as the leading factor behind the higher values of all the RESs in the peak sunshine hours.

\section{E. Hybrid System Application to Electric Vehicle}

Among the major objectives of this research is to investigate the potential of the designed HRES for Electric Vehicles (EVs) charging. BSC-P1 brushless DC Motor mini electric vehicle with the electricity demand of $0.8 \mathrm{~kW}$ for charging the five (5) $12 \mathrm{~V} / 38 \mathrm{Ah}$ lead-acid batteries delivering power to the brushless DC motor for the vehicle propulsion is the selected EV in this study. The EV operates with fast charging mode from the Electric Vehicle SupplyEquipment (EVSE) operating at $220 \mathrm{~V}$ on $50 \mathrm{~Hz}$. To present a clear demand dynamics, the EV electricity demand is distributed across the number of hours suitable for the EV to be charged during the idle periods. The EV is scheduled to shuttle within the university for two shuttle times. The periods of shuttles are 9am-11am and $5 \mathrm{pm}-9 \mathrm{pm}$. The typical household electricity demand and the EV electricity demand are combined to understand the overall performance of the system.

Preview Fig. 13 it can be realised that that the performance of the HRES during the sunshine hours was very promising in delivering power to the loads. The results clearly show that the system was able to supply power to the demand during early morning hours, from the WECs output. Although the power delivery by the system during sunshine hours was not able to meet the total demand, the deficit was covered during the sunshine hours. During the sunny hours, the results revealed that huge surplus power was employed by the system in charging the BESS.

It can be seen from Fig. 13 that both the simulated and experimental results can be able to deliver the total electricity demand from the loads with huge excess power. Based on the electricity demand of the EV and the total power demand of the BESS, the analysis of the results revealed that the proposed HRES was able to supply the total electricity demand of the BSC-P1 electric campus shuttle and the BESS charging with surplus power to the grid. The results observed in this section revealed that the proposed novel technique addressed the intermittency effect of renewable energy resources in electricity generation at both simulation and validation.

Table 5: Correlation Coefficient ( $\mathrm{r}$ ) values PVGIS5 and real parameters

\begin{tabular}{ll}
\hline \multicolumn{2}{l}{} \\
\hline Parameter & $\begin{array}{l}\text { Correlation Coefficient } \\
\text { (r) Values }\end{array}$ \\
\hline Wind speed & $0.98 \%$ \\
Wind power output & 0.154 \\
Solar & $0.10 \%$ \\
Solar power output & 0.098 \\
Temperature & 0.239 \\
Hybrid output & $0.66 \%$
\end{tabular}

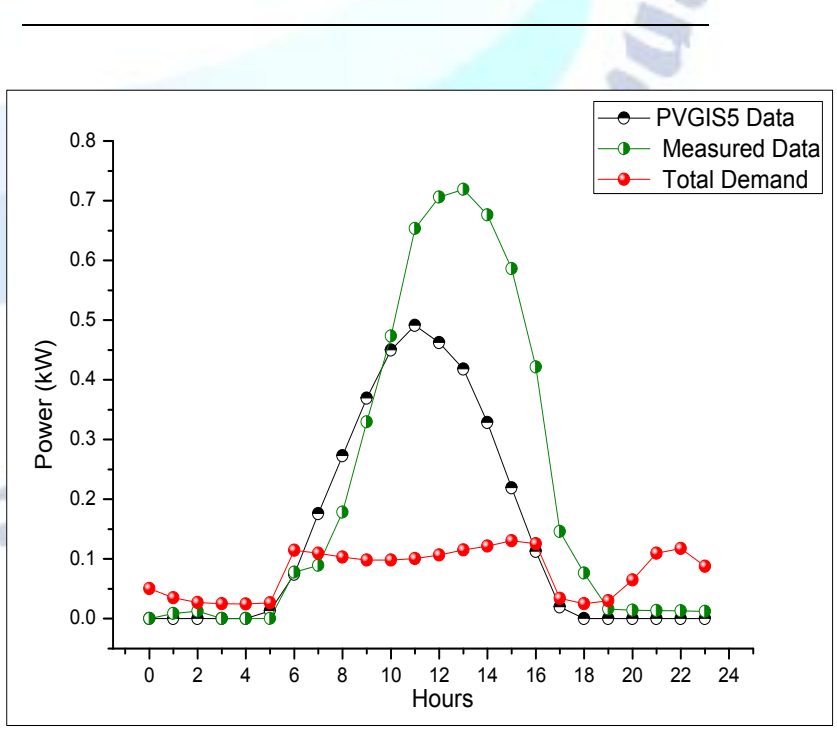

(a) 


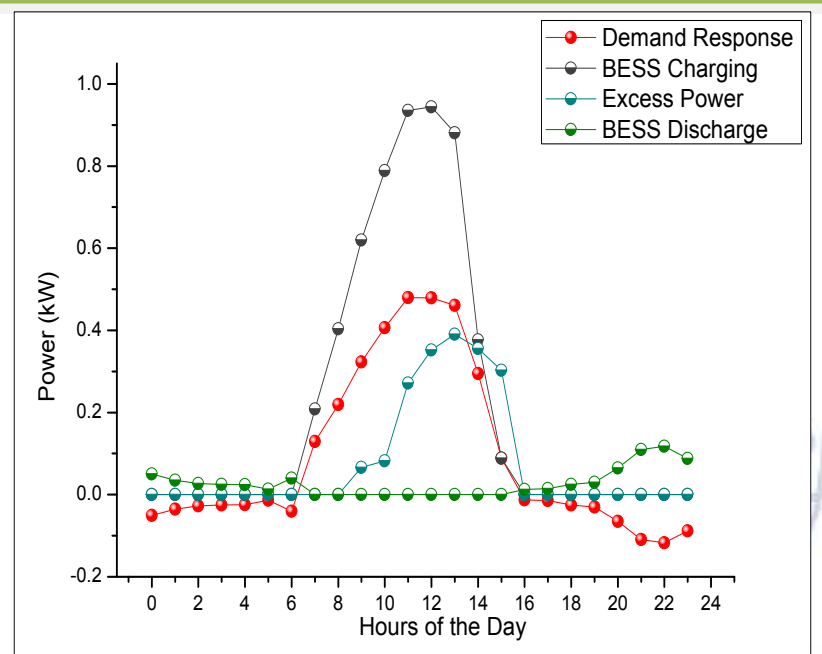

(b)

Fig. 13. Hybrid system performance across the typical day in all the seasons: a) comparison between experimentally measured data and PVGIS5 data (b) demand analysis of the HRES

\section{Conclusion}

A grid-independent wind/PV/battery-based HRES is designed analysed and validated using a novel approach for the first time as optimum to fulfill the typical household electricity demand and mini electric campus shuttle. The solar PV-wind hybrid plant is the first of its kind across the district and as such, potential studies of the hybrid system is required. The study assesses the potential studies of the hybrid system across the seasons of the year using PVGIS5 satellite data before the overall system validation. The first step of the study is the extraction and sorting the satellite datasets to the seasons of the year and typical day across the seasons of the year using MATLAB Simulink. Using the extracted datasets, the finest potential evaluation of the hybrid system is established.

The simulation results obtained on the designed HRES demonstrated the effectiveness of all the adopted methods in enhancing the modelling accuracy of renewable electricity systems in electricity generation. The results of the system simulation show that there exists a direct relationship between solar energy and wind energy in electricity generation. The distinctive profiles of wind and solar resources show that the combination of the two renewable energy systems in the form of hybrid can offer a unique opportunity in eliminating the intermittent effect of renewable energy resources in electricity generation. As admitted in many cases, the predicted performance in simulated models usually surpasses the real hybrid plant, which is in contradiction with the

\section{findings of this study.}

The simulation and the validation results all demonstrated that the system could deliver full electricity demand of typical household as well as, the $800 \mathrm{~W}$ electricity demand of BSC-P1 electric campus shuttle. Further analysis of the results revealed that $100 \%$ BESS charging could be achieved and the battery capacity was never reached at all-time, which is indicating the viability of the system in supplying uninterrupted power to electricity demand.

\section{ACKNOWLEDGMENT}

The authors gratefully acknowledge the Central University of Kerala, Kebbi State University of Science and Technology, Aliero, Kebbi State Nigeria for making the resources and materials for the success of this research.

\section{REFERENCES}

[1] Siva Raman Sharvini, Zainura Zainon Noor, Chun Shiong Chong, Lindsay C. Stringer, Rafiu Olasunkanmi Yusuf. Energy consumption trends and their linkages with renewable energy policies in East and Southeast Asian countries: Challenges and opportunities (2018). Sustainable Environment Research, Volume 28, pp. 257-266.

[2] Jules Chuang, Hsing-Lung Lien, Walter Den, Luvian Iskandar, Pei-Hsuan Liao (2018). The relationship between electricity emission factor and renewable energy certificate: The free rider and outsider effect. Sustainable Environment Research, Volume, 28, pp. 422-429.

[3] Moutinho Victor, Margarita Robaina (2016). Is the share of renewable energy sources determining the $\mathrm{CO}_{2} \mathrm{kWh}$ and income relation in electricity generation? Renewableand Sustainable Energy Reviews, Volume, 65, pp. 902-914.

[4] Bonfils Safari (2011) Modelling wind speed and wind power distributions in Rwanda. Renewable and Sustainable Energy Reviews, Volume 15, pp. 925-935.

[5] Gwani, M., and Abubakar, G. A. (2017). Power sector challenges and renewable energy potentials in Nigeria. International Journal of Engineering Research and General Science. Volume 5, Issue 1, pp. 76-84.

[6] Catarina Matos R, Júlio Carneiro F., Patrícia Silva P. (2019) Overview of Large-Scale Underground Energy Storage Technologies for Integration of Renewable Energies and Criteria for Reservoir Identification. Journal of Energy Storage, Volume 21, pp. 241-258.

[7] Taher Maatallah, Souheil El Alimi, Anour Wajdi Dahmouni, Sassi Ben Nasrallah (2013). Wind power assessment and evaluation of electricity generation in the Gulf of Tunis, Tunisia, Sustainable Cities Society, Volume 6, pp. 1-10.

[8] Loiy Al-Ghussain, Onur Taylan, Derek K. Baker (2019). An investigation of optimum PV and wind energy system capacities for alternate short and long-term energy storage sizing methodologies. International Journal of Energy Research, Volume 43, Issue 1, pp. 204-218.

[9] Abubakar G., Muthukumar A. and Muthuchamy, M. (2019) Assessment of small Scale Solar PV Electricity Generation Potential using A Novel Technique. International Journal on Emerging Technologies, Volume 10, Issue 4, pp. 111-118. 
[10] Hasan Mehrjerdia and Reza Hemmati (2019). Electric vehicle charging station with multilevel charging infrastructure and hybrid solar-battery-diesel generation incorporating comfort of drivers. Journal of Energy Storage, Volume 26, pp. 100924.

[11] Krishan Om and Sathans Suhag (2019). Techno-economic analysis of a hybrid renewable energy system for an energy poor rural community. Journal of Energy Storage. Volume 23, pp. 305-319.

[12] Shuvankar Podder, Raihan Sayeed Khan, and Shah Md Ashraful Alam Mohon (2015). The Technical and Economic Study of Solar-Wind Hybrid Energy System in Coastal Area of Chittagong, Bangladesh. Jornal of Renewable. Energy, Volume 2015, pp. 10.

[13] Edmond Baranesa, Julien Jacqminb, Jean-Christophe Poudouc (2017). Non-renewable and intermittent renewable energy sources: Friends and foes? Energy Policy. Volume 111, pp. 58-67.

[14] Urzúa IA, Olmedo JC, Sauma EE (2016). Impact of intermittent non-conventional renewable generation in the costs of the Chilean main power system Review Article. Renewable and Sustainable Energy Reviews, Volume 60, pp. 810-821.

[15] Camille Cany, Christine Mansilla, Pascal da Costa, Gilles Mathonnière, Thierry Duquesnoy, Anne Baschwitz (2016). Nuclear and intermittent renewables: Two compatible supply options? The case of the French power mix', Energy Policy, Volume 95, pp. 135-146.

[16] Diafa Said, Gilles Notton, Djamila Diafa (2013). Technical and economic assessment of wind farm power generation at Adrar in Southern Algeria, The Mediterranean Green Energy Forum 2013, MGEF-2013. Energy Procedia, Volume 42, pp. 53-62.

[17] Zeyu Ding, Hongjuan Hou, Gang Yu, Eric Hu, Liqiang Duan, Jin Zhao (2019). Performance analysis of a wind-solar hybrid power generation system. Energy Conversion and Management, Volume 81, pp. 223-234.

[18] Daniel-Ioan Stroe, Andreea Zaharof, Florin Iov (2018). Power and Energy Management with Battery Storage for a Hybrid Residential PV-Wind System - A Case Study for Denmark. Energy Procedia, Volume 155, pp. 464-477.

[19] Subhadeep Bhattacharjee, Shantanu Acharya (2015). PV-wind hybrid power option for a low wind topography. Energy Conversion andManagement, Volume 89, pp. 942-954.

[20] Hassan Fathabadi (2018). Utilizing solar and wind energy in plug-in hybrid electric vehicles. Energy Conversion and Management, Volume 156, pp. 317-328.

[21] BaneshiM and Hadianfard F (2016). Techno-economic feasibility of hybrid diesel/PV/wind/battery electricity generation systems for non-residential large electricity consumers under southern Iran climate conditions, Energy Conversion and Management, Volume 127, pp. 233-244.

[22] Amutha W.M., Rajini V (2016). Cost benefit and technical analysis of rural electrification alternatives in southern India using HOMER, Renewable and Sustainable Energy Reviews, Volume 62, pp. 236-246.

[23] Diego B. Carvalho, Eduardo C. Guardia, José W. Marangon Lima (2019). Technical-economic analysis of the insertion of PV power into a wind-solar hybrid system. Solar Energy, Volume 191, pp 530-539.

[24] Charrouf, O., Betka, A., Abdeddaim, S., Ghamri, A (2020). Artificial Neural Network power manager for hybrid PV-wind desalination system. Mathematicsand Computers in Simulation, Volume 67, pp. 443-460.

[25] Oluwarotimi Delano Thierry Odou, Ramchandra Bhandari, Rabani Adamou (2020). Hybrid off-grid renewable power system for sustainable rural electrification in Benin. Renewable Energies, Volume 45, pp. 1266-1279.

[26] Dhunnya Z. A, Doorga, J. R.S., Allam, Z, Lollchund M. R, Boojhawon R (2019). Identification of optimal wind, solar and hybrid wind-solar farming sites using fuzzy logic modelling. Energy, Volume 188, pp. 116056.

[27] Abhishek Tiwary, Stanislava Spasova, Ian D. Williams (2019). A community-scale hybrid energy system integrating biomass for localised solid waste and renewable energy solution: Evaluations in UK and Bulgaria. Renewable Energies, Volume 139, pp. 960-967.

[28] Jameel Ahmad, Muhammad Imran, Abdullah Khalid, Waseem Iqbal, Syed Rehan Ashraf, Muhammad Adnan, Syed Farooq Ali, Khawar Siddique Khokhar (2018). Techno economic analysis of a wind-photovoltaic-biomass hybrid renewable energy system for rural electrification: A case study of Kallar Kahar. Energy. Volume 148, pp. 208-234.

[29] Golbarg Rohani, Mutasim Nour (2014). Techno-economical analysis of stand-alone hybrid renewable power system for Ras Musherib in United Arab Emirates. Energy, Volume 64, pp. 28-841.

[30] Wang Jianhui, Cong Liu, Dan Ton, Yan Zhou, Jinho Kim, Anantray Vyas (2011). Impact of plug-in hybrid electric vehicles on power systems with demand response and wind power. Energy Policy, Volume 39, issue 7, pp. 4016-4021.

[31] Denholm Paul, Michael Kuss, Robert M. Margolis (2013). Co-benefits of large-scale plug-in hybrid electric vehicle and solar PV deployment. Journal of Power Sources, Volume 236, pp. 350-356.

[32] Pedro Nunes, Tiago Farias, Miguel C. Brito. Enabling solar electricity with electric vehicles smart charging. Energy. 2015; 87: 10-20.

[33] Nathaniel Pearre, S. and Lukas Swan G. Electric vehicle charging to support renewable energy integration in a capacity constrained electricity grid. Energ. Convers. Manage. 2016; 109: 130-139.

[34] Taibi Emanuele, Carlos Fernández del Valle, Mark Howells. Strategies for solar and wind integration by leveraging flexibility from electric vehicles: the Barbados case study. Energy. 2018; 164: 65-78.

[35] Domenico Mazzeo. Solar and wind assisted heat pump to meet the building air conditioning and electric energy demand in the presence of an electric vehicle charging station and battery storage. J. Clean. Prod. 2019; 213: 1228-1250.

[36] Mehrjerdi Hasan, Reza Hemmati, 2020. Coordination of vehicle-to-home and renewable capacity resources for energy management in resilience and self-healing building. Renew. Energy. 2020; 146: 568-579.

[37] Jouni K J, Sampsa Hyysalo. Renewable and microgeneration of heat and electricity-review on common and missing socio-technical configurations. Renew Sust. Energ. Rev. 2015; 49: 857-870

[38] Prakash Kumar K, Saravanan B. Day ahead scheduling of generation and storage in a microgrid considering demand Side management. J. Energy Storage. 2019; 21: 78-86.

[39] Vijayalakshmi S, Girish G, Keshav Singhania. Role of Renewable Energy in Indian Power Sector. Energy Procedia. 2017; 138: 1073-1078.

[40] Vedachalam N, Surendar S, Srinivasalu S. An assessment of decarbonization in the strategic Indian electricity generation sector. Electr. J. 2017; 30:5: 47-53

[41] Umesh Kumar Shukla and Seema Sharma. The potential of electricity imports to meet future electricity requirements in India. Electr. J. 2017; 30:3: 71-84

[42] Blumsack B. and Kelsey R. Cost and Emissions Implications of Coupling Wind and Solar Power. Smart Grid 
and Renew. Energ. 2012; 3: 308-315.

[43] Mohammad Sameti, Alibakhsh Kasaeian and Fatemeh RaziAstaraie. Simulation of a ZEB Electrical Balance with a Hybrid Small Wind/PV. Sustainable Energies. 2014; 2:1: 5-11.

[44] Adam K, Victoria H, James G, Thomas K, Catherine SE Bale, Alison ST. Methodologies for city-scale assessment of renewable energy generation potential to inform strategic energy infrastructure investment. Cities. 2016; 54: 45-56.

[45] Vijayalakshmi S, Girish G, Keshav Singhania. Role of Renewable Energy in Indian Power Sector, Energy Procedia. 2017; 138: 1073-1078.

[46] Walker S. Building mounted wind turbines and their suitability for the urban scale-A review of methods of estimating urban wind resource. Energ. Buildings. 2011; 43: $1852-1862$.

[47] Sukam. Sukam 150 watt 12-volt solar panel. 2018. https://www.loomsolar.com/products/sukam-150-watt-1 2-v-solar-panel-polycrystalline Accessed 30 June 2018.

[48] Koehl Michael, Markus Heck, Stefan Wiesmeier, Jochen Wirth. Modeling of the nominal operating cell temperature based on outdoor weathering. Sol. Energy Mater. Sol. Cells. 2011; 95: 1638-1646.

[49] Schwingshackl C, Petittaa M, Wagnera JE, Belluardo G, Moser D, Castellia M, et al. Wind effect on PV module temperature: Analysis of different techniques for an accurate estimation. Energy Procedia. 2013; 40: 77-86.

[50] Thomas Huld, Magda Moner-Girona and Akos Kriston. Geospatial Analysis of Photovoltaic Mini-Grid System Performance', Energies. 2017; 10:218: 1-22.

[51] Gado A, Gwani M, NaAllah M. and Musa A. Wind Power Potential Analysis of Sokoto North western Nigeria. Int. J. Chem. Environ. Eng. 2015; 6:6: 369-373.

[52] Krzysztof Gajowniczek and Tomasz Zabkowski. Two-Stage Electricity Demand Modelling Using Machine Learning Algorithms. Energies. 2017; 10: 1547.

[53] José Luis Ramírez-Mendiola, Philipp Grünewald, Nick Eyre. The diversity of residential electricity demand -A comparative analysis of metered and simulated data. Energ. Buildings. 2017; 151: 121-131.

[54] Widén J, Molin A, Ellegård K. Models of domestic occupancy, activities and energy use based on time-use data: deterministic and stochastic approaches with application to various building-related simulations. J. Build. Perform Simu. 2012; 5:1: 27-44

[55] Ozturk HK, Ceylan H, Canyurt OE, Hepbasli A (2005). Electricity estimation using genetic algorithm approach: A case study of Turkey. Energy. Volume 30, pp. 1003-1012.

[56] Eco-Worthy. 400W Wind Turbine Generator System with Controller for $12 \mathrm{~V} / 24 \mathrm{~V}$. 2018. https://www.eco-worthy.com/collections/wind-turbine. Accessed 11 December 2018.

[57] BSC. BSC-P1 electric car for passenger. https://electric-tuk-tukza.weebly.com/uploads/7/8/9/8 /78983418/specification_of_bsc-p1.pdf2018. Accessed 12 January 2018.

[58] Doug Kettles. Electric Vehicle Charging Technology Analysis and Standards. Florida Solar Energy Centre. FSEC Report Number: FSEC-CR-1996-15.2015. http://www.fsec.ucf.edu/en/publications/pdf/FSEC-CR1996-15.pdf. Accessed 11 January 2019.

[59] Tremblay O, Dessaint LA, Dekkiche AI (2007). Model for the dynamic simulation of hybrid electric vehicles. IEEE Vehicle Power and Propulsion Conference 2007, pp. 284-289.

[60] Om Krishan, Sathans Suhag (2019). Techno-economic analysis of a hybrid renewable energy system for an energy poor rural community. Journal of Energy Storage, Volume 23, pp. 305-319.

[61] Thapar Vinay, Gayatri Agnihotri and Vinod Krishna Sethi. Critical analysis of methods for mathematical modelling of wind turbines. Renewable Energy, Volume 36, Issue 11, pp. 3166-3177.

[62] Lydia M, Suresh Kumar S, Immanuel Selvakumar A, Edwin Prem K G (2014). A comprehensive review on wind turbine power curve modelling techniques. Renewable and Sustainable Energy Reviews, Volume 30, pp. 452-460.

[63] Graham S (2007). Characteristics of the UK wind resource: Long-term patterns and relationship to electricity demand', Energy Policy, Volume 35, pp. 112-127.

[64] Azad Hanieh Borhan, Saad Mekhilef, Vellapa Gounder Ganapathy (2014). Long-term wind speed forecasting and general pattern recognition using neural networks. IEEE Transactions Sustainable Energy, Volume 5, Issue 2, pp. 546-553.

[65] Gado Abubakar, Anbazhagi Muthukumar, Muthukumar Muthuchamy (2019). Investigation of small-scale wind electricity generation using spline interpolation model. International Journal of Scientific Research and Reviews, Volume 8, Issue 2, pp. 3080-3100.

[66] Nelson D. B, Nehrir M. H, Wang C (2006). Unit sizing and cost analysis of hybrid stand-alone wind/PV/fuel cell power generation systems. Renew. Energy, Volume 31, pp. 1641-1656.

[67] Mustafa Engin (2013). Sizing and Simulation of PV-Wind Hybrid Power System. International Journal Photoenergy, Volume 2013, pp. 1-10.

[68] Sami S. and Icaza D (2015). Modeling and Simulation of Hybrid Solar Photovoltaic, Wind turbine and Hydraulic Power System. International Journal of Engineering, Science and Technology, Volume 7, Issue 9, pp. 304-317.

[69] Lennart Petersen, Florin Iov, German Claudio Tarnowski, Vahan Gevorgian, Przemyslaw Koralewicz and Daniel-Ioan Stroe (2019). Validating Performance Models for Hybrid Power Plant Control Assessment. Energies. Volume 12, pp. 4330. 